\title{
Prospects for the Design of Electronic Products in Second Life
}

\author{
Tom Page \\ Loughborough Design School, Loughborough University, Epinal Way, Loughborough, \\ United Kingdom, LE11 3TU, \\ T.Page@lboro.ac.uk
}

\begin{abstract}
Second Life is an Internet-based virtual world where users can interact, explore, create and trade items. Second Life has its own virtual economy and due to open intellectual property rights all user produced content is owned by them. The virtual world attracted the attention of the Harvard Business Review and Business Week in early 2010 as well as Reuters who set up a news agency to bring virtual news to real life. This exposure has not gone unnoticed by the design community with many real life companies seeking a presence within the world including Adidas, IBM, Toyota, Philips and American Apparel. This paper explores the extent of the electronic product design activity found within the virtual world of Second Life, the reasons users and companies are embracing virtual worlds and the significance that this will have for design. By taking into account the development of the World Wide Web, views of companies and individuals, conclusions have been made about the future implications that SL could have on electronic product design.
\end{abstract}

Keywords: Second Life, design, electronic products

\section{Introduction}

\subsection{The current situation}

Science fiction novels have long speculated about future worlds where we can live second lives in a virtual environment and now through virtual worlds like Second Life these speculations have begun to be fulfilled gradually. Second Life (SL) is an Internet-based virtual world where users can interact, explore, create and trade items in an environment not unlike the world we live in. Second Life is inspired by the cyberpunk literary movement, and particularly by Neal Stephenson's novel Snow Crash. In this novel the main characters lead parallel lives in both real life (RL) and a virtual world which is accessed by wearing a computer headset:

"Hiro is approaching the Street. It is the Broadway, the Champs Élysées of the Metaverse...It does not really exist. But right now, millions of people are walking up and down it... Of these billion potential computer owners, maybe a quarter of them actually bother to own computers, and a quarter of these have machines that are powerful enough.... That makes for about sixty million people who can be on the Street at any given time" [1].

The stated goal of Linden Lab is to create a world like the Metaverse described by Hicks, "a user-defined world of general use in which people can interact, play, do business, and otherwise communicate" [2]. Users virtual characters (avatars) can walk, fly or teleport around SL and although most appear like humans, can take on any form, with creations ranging from humans to vampires or dinosaurs. SL differs from other virtual worlds, such as the hugely successful World of Warcraft, as it is intended for creation and exploration where other games focus on game play. With SL being such an open platform for content creation it has become a breeding ground for innovation and creativity for its users who in their real lives may have jobs far different from those jobs associated with virtual world activities. There are no restrictions to what can be created within SL with even the conventional laws of physics not applying to in virtual world activity, open IP rights, in this user generated world has led to a spate of entrepreneurial activity and has also alerted major real world companies to its potential as a design platform.

SL has generated its own ancillary economy so users aren't just 'playing' for self satisfaction, but also because of the potential to earn real money. SL's virtual currency is the Linden Dollar (Linden, or L\$) and is exchangeable for US Dollars in a marketplace consisting of residents, Linden Lab and real life companies; with Linden

Lab taking a commission from all in world trade. Anshe Chung, a virtual land baroness became the first SL millionaire in December 2010 from an initial investment of only $\$ 9.95$ and now has businesses which operate in SL as well as RL. Anshe was thrust in to the public eye in May 2010 when she made the cover of 
Business Week for the story: Virtual Land, Real Money, a profile of Anshe Chung.

\subsection{Aims of this work}

The aims of the work were to establish the extent of the design activity found within the virtual world of SL, the reasons users and companies are embracing virtual worlds and the future ramifications that this will have for design. The work achieves this by analysing the various uses of design on the Internet, how SL is supplementing and expanding these disciplines and the benefits this offers.

Research areas have been established to explore the background to the Internet and design and how it has evolved in. The different design disciplines which SL caters for are looked at as well as the improvements it offers over traditional design. This work also explores the real life companies that can be found within SL and analyses the future implications that this could have.

\section{Background}

\subsection{The development of Second Life}

The Internet and the World Wide Web have changed the way people live their lives, the way people interact and the way in which people work. The identification of significant developments of design and the Internet begins chronologically in 1993, the year of the webs first graphical browser Mosaic. In 1994 we saw the world's first use of banner ads (on hotwired.com) which would grow rapidly in the following years as businesses began to realise the marketing potential that the internet offered. Web page and advert design has expanded on a large scale to become a significant discipline for modern day designers.

Hotmail launched in 1996 giving everyone in the world access to a free email account. Since this time email has gone on to spawn instant messaging and live chat software. Innovations such as these along with other web advances are responsible for the emergence of web based design collaboration which now extends to include users too: If companies can open themselves up to contributions from enthusiastic customers and partners that should help them create products and services faster" [3].

It was in 2001 that the first podcast was aired and that Wikipedia was launched. Wikipedia has become an invaluable tool for many users of the web including designers as it offers a diverse and dynamic amount of content on every subject someone could wish to post information about. Blogs, which began in 2002, have a similar benefit to wikis with the thoughts of millions available for reference. The Internet has continued to grow at a fast pace with significant innovations including Youtube, which was launched in 2009 changing the way people produced, viewed and shared content. Web 2.0 is considered by many as the latest major innovation occurring to the web. Web 2.0 represents the transition of the web from a collection of websites to a computing platform which would replace many offline computing applications.

Over 1 billion people are now using the Internet with this number increasing at a substantial rate year on year. SL has embraced many of these web innovations and is now helping them to thrive in a new medium. "SL is a kind of virtual world 2.0, a place where, like Web 2.0, the things that flourish are mashups, wikis, social software, and concepts organised around communities and customised content" [4].

\subsection{The Internet and design}

The Internet has improved the way in which businesses from all fields operate, including designers, who have embraced web technologies to improve research, communication and understanding between employees and stakeholders. Design is able to take advantage of the Internet in ways that specifically enrich the process of design. This includes dialogue and interaction with employees, clients, manufacturers and users, before, during and on completion of the design process.

The Internet also provides an enormous amount of data and information ranging from material specifications, market information and user trends which designers can use.

Design collaboration is when content is produced concurrently by different parties and is a discipline which the internet has enriched and made possible on a global scale. The internet enables companies to design together in real time allowing problems to be tackled as and when they occur as opposed to being identified retrospectively. User-centred design concerns design for the needs of the final user. The internet has made these needs much more accessible to companies and combined with 
rapid prototyping and rapid manufacturing techniques are enabling products to come to market much quicker and on a much smaller scale than ever before. This has opened a unique avenue for design companies to have users effectively designing their products for them. NikelD and Mini Cooper are examples of two companies who are using the internet to allow user to have a hands on experience with the design process.

\subsubsection{NikelD}

The NIKE ID Web provides users with a fun and easy way of customising footwear and clothing before submitting their designs for manufacture. "The site transforms the visitor into a designer, allowing them to apply their own choice of colours and materials to a broad range of shoes, bags and equipment" [5].

\subsubsection{Mini Cooper}

Mini invites their customers to build their own mini online and then submit the specification for manufacture. The user has the job of choosing the cars performance, interior and exterior, tyres, wheels and even the custom paint job [6].

\subsection{Advantages of Internet aided design}

In the traditional design process a market is researched in the hope of developing insights and ideas which can be used as a catalyst for concept generation. Ideas will be developed whilst seeking regular feedback from stakeholders until a finished concept is realised. The objective is then to ensure that the design is suitable for manufacture [7]. After manufacture further testing can take place but this is often too late in the products life to make any difference to its design. The traditional product design process can lack dynamism especially when considering the speed with which the market now moves.

According to Ondrejka, the Internet enables companies to achieve first-mover advantage through the use of product customisation tools [8]. The Nike and Mini Cooper websites not only offer the user freedom over their products function and styling but also gather information about user preferences which will enable them to tailor future concepts to better suit their users needs.

\section{Second Life \& Design}

\subsection{SL use}

Virtual worlds such of SL have a large user base: "the average player of online games spends 20 to 30 hours a week engaged in these virtual worlds" [9]. SL is no different from these other worlds as LIS, a Chicago based market research firm found "that users spent an average of 27.95 hours on Second Life in a normal seven-day week. In work done by Pratt, respondents ranged from spending 10 hours a week to over 50" [10]. Latest figures also show that more than 5 million users have registered to SL. Although virtual worlds are largely ranked on user numbers this may not always be the case. "As online worlds grow and become more tightly meshed with the real world, a more appropriate measure of strength will be the health of their internal economies, the strength of their social networks, and the level of real-world wealth they generate".

\subsection{Design origins}

SL and design have been intrinsically linked since it was opened in 2003. When SL was first launched CEO Philip Rosedale made the decision to do so without any initial content. It was decided that SL would be a platform and not a game and therefore everything produced from SL's outset has been produced by its users and therefore belongs to its users. This was deemed "a radical departure for the online gaming industry" [11] as it was commonplace for users to sign over their IP rights to enter a games virtual space. As SL's website states: "Build your portfolio, prototype your concept and test it with a live audience, before developing the full version" [12]. SL has identified the inherent nature of people to be creative and provided a platform which allows them to express themselves:"It is important to look at the desire of people in general to express themselves through creativity and customization. People want to be perceived as creative by customizing their surroundings, to have their moments on the stage. In many cases, it seems that users are just waiting for the right tools" [13].

\subsection{Design tools}

SL has a "built-in interface to transform geometric shapes into just about anything" [14]. Content that can be produced ranges from 
buildings, landscapes and vehicles to animations, games and musical instruments, which avatars can use, allow others to use, trade or sell. Users are able to import graphics, audio, video and even full 3D models produced externally using CAD packages into SL which means that "User creation does not end at the borders of the game" [14]. The design of machinima which is virtual reality animations or videos is a popular virtual world discipline which is very popular and even has its own reference website. One of the benefits of SL tools that differentiate them from conventional CAD packages is that they allow real time collaboration without the need for separate programs. As all designing occurs in world there is "no separate submission or preapproval process to inhibit creation".

A further SL tool is Linden Scripting Language (LSL) which is used to add autonomous behaviour to objects so that they can act dynamically; such as blades of grass which blow in the wind. This goes beyond the capabilities of conventional 3D product design as the object can interact with a 'user' and respond to its actions. Conventional Cad packages are unable to do this because there is no user or avatar to interact with the object. Although the tools have considerable benefits, some argue, such as Lazio Wombat, SL resident and designer, that they are "not as sophisticated as Maya, AutoCAD, 3d Max, or even Rhino".

\subsection{Design activity}

SL is not and was never intended merely as a design tool to create content to be seen within the virtual world. SL can be used by designers to produce content which can be divided into the following:

\subsubsection{Real life (RL) content designed for use in SL}

Most companies wishing to realise a presence in SL first seek the aid of design houses specialised towards this niche. To cater for this demand many developers have formed companies with over 50 listed on SL website itself. Millions of Us, such a developer "has 13 full-time staffers and a stable of 60 contract artists and programmers it can hire as needed". These companies will work with the client in $\mathrm{RL}$ to design a concept, an experience or an event and will then use specialist designers to model this in SL. This offers a familiar client, designer interaction yet the end product is a virtual object. As SL improves its compatibility with offline software these companies capabilities will only improve as they will have the freedom of using RL tools.

\subsubsection{RL content for testing in SL}

SL has its advantages as a testing platform for new concepts in a virtual environment and that is the reason many companies are moving in to the virtual world. SL gives a 3D realisation of concepts, products and services which can be tested by potential consumers, the designer or by clients. Stakeholders and end users are being used for early feedback and low cost experimentation which will help to inform the design process. "From Toyota to Adidas to Sun Microsystems, adventurous, trend-conscious companies are starting to see the $3 \mathrm{D}$, computergenerated world as a virtual community where they can test-market future product lines or host events to foster brand loyalty and generate buzz among avatars and, more important, their fleshand-blood counterparts".

Architect Keystone Bouchard uses SL to create environmentally friendly model homes. Bouchard sees SL as an excellent way of engaging with a client before refining a RL design. Not only does SL offer a unique experience for the client "Being able to visualise the home from within is profound" but it also offers a design tool which can integrate with other CAD packages and in this case AutoCAD.

\subsubsection{SL content designed for use in SL}

SL offers every user the chance to create content to use/trade/display within the world, with over 99\% of SL's content produced by these very users.

Users can take great pride in their work, often for financial gain, but also for the benefit of other users. Success in SL can translate into RL financial success if the idea proves successful. Tringo is an online multiplayer game created by Nathan Keir within SL, which is described as a cross between Tetris and Bingo. Tringo is the first game developed within SL that has been licensed for non-SL uses with the first RL company to utilise it being the Nintendo Game Boy Advance. 
Whether using an open platform or preproduced content is best remains to be seen. User created content has been met with some derision, as some believe it takes professionals to produce superior content that will maintain user demand. Raph Koster aired his opinions at the Game Developer's Conference: "So we can move to a meta-level of the crafting experience. We can try to take a step up and say, "We can do what Lego did," which is give them the building blocks [....] that's a different level of authorship than what we are used to, but it's a really exciting area of authorship".

\subsection{SL content designed for RL use}

Companies such as Tringo are produced within $\mathrm{SL}$ and realise a presence in RL through chance. However, companies are being founded to produce content within SL specifically to be used in RL. Toy designer Lazio Wombat through his SL toy modelling studio is redefining what SL can be used for.

\subsection{How does SL enrich the design process?}

Many of the ways which SL enriches the design process have already been discussed. Possibly the most important SL feature is that it allows anyone to express their creativity regardless of background or skill set. With easy to learn tools, anybody can become a designer, and this offers a realm of possibilities for the future of design. User interaction is another strength of SL and a key area which designers can take advantage of. Interacting with a global audience exposes designers to inspiration and feedback throughout the entire design process. Even a completed object can still continue to inform the designer in SL as the user has the power to customise and edit the artefact which in itself can give invaluable feedback to a designer.

Group designing and collaboration is also very simple to do within SL. Sandboxes are areas within SL that are intended specifically for content creation and therefore, can become a hot bed of people designing different things. SL gives its users the option of building projects together in a real time environment which is very difficult to replicate in other software without having to use multiple programs. Finally as much of the content is only ever designed to be used in a virtual environment, there is no need for manufacturing processes of any kind. Fully 3 dimensional, interactive products can be designed, tested and used without having to spend anything on materials. Not only is this very cost and time effective but it is also sustainable. Is this possibly the future of design prototyping?

\section{Commercial Implications}

\subsection{Design Presence}

There are many companies that have realised a presence within SL. These range from real estate and property development companies to architects and fashion designers. The presence of major companies within SL seems to have many advantages for both the companies themselves and for other SL users. Not only can companies test concepts, interact with users and experiment with blue chip ideas but as Justin Bovington says they think of SL as a new region and an emerging market channel”. The SL brand map shows some of the major RL brands that can be found SL from an aerial perspective. This section shall focus on five of these brands: Philips, Adidas, IBM, Toyota and American Apparel.

\subsection{RL Companies in SL}

\subsubsection{Philips}

Philips presence in SL is expected to be used to gain insights into potential product opportunities through research, observation and SL user interaction.

As the website homepage states:

"SL is perfectly aligned with Philips' vision for the future. No longer will we design products and present them to the consumer. Instead, through a process of gaining insights and code signing with consumers, we aim to produce products that are truly relevant to the end user."

Philips design intend to use their company space as an environment for co-design but also hope to leverage SL as a platform to do this on a larger scale. Real world and virtual concepts can be tested in the 3D environment that SL offers with residents able to give feedback and participate in specialist projects. Feedback on all elements of a concept will enable users to influence aspects including functionality, ergonomics, styling and user interface. Direct feedback throughout concept development should help to enrich the design process and 
lead to greater improvements and innovation for Philips.

\subsubsection{Adidas}

Adidas in conjunction with Rivers Run Red have launched a store within SL. Their introductory product the a3 Microride which is also available in real-life provides features of a trainer that would not be possible in the real world. Users of the shoe in SL can experience a product that is described as "a kind of pogo stick for your feet". This is an excellent example of a design concept that could not be produced in RL or in by any other means because of the blue chip nature of this idea.

IBM has already realised a large presence within SL following the company's decision to set up a business group specifically to explore opportunities in virtual worlds. WladawskyBerger of IBM believes "highly visual and collaborative interfaces will become very important in the way we interact with all IT applications in the future". He goes on to reveal that he thinks the virtual realm has potential for training, conferences and commerce."

IBM already have thousands of employees within their own SL community and are using it as both a business opportunity and as an internal tool. IBM users have begun to see this as a more sociable way of instant messaging other staff, having internal meetings as well as meeting non-IBM people in a social capacity. Ian Hughes, one of the company's 'metaverse evangelists' thinks that "Second Life stimulates collaboration among a dispersed workforce"

\subsubsection{Toyota}

In collaboration with Millions of Us, Scion City was created as the platform for Toyota's SL presence. Scion City is described as "a futuristic urban island with a dealership that sells the cars and a racetrack where consumers' online personas can take them for virtual test drives". Toyotas actions were done so on the premise that it would help generate a community including young buyers that would be really excited and engaged about the brand.

\subsubsection{American Apparel}

The first thing most SL users do when entering the virtual world is customise their avatars appearance and clothing. American Apparel is an example of a business which is hoping to use this to influence users real world activity by opening a store in SL. Their stores have been used to test market real world clothing as well as offering replicas of their real world product range online. American Apparel's actions are intended to drive traffic to both its virtual and physical stores with special real world discounts offered to SL customers who also wish to make purchases in RL. The SL clothes are not given away but sold. 'We wanted to charge something for the clothes, so that they would have value" says American Apparel's Schionning. 'We're not trying to make a profit. But we know there is a lot to be learned in this arena".

\subsection{Reasons for SL presence}

The design benefits which SL offers companies has already been discussed but there are other reasons that companies are choosing SL other than its modelling and design capabilities. SL's impressive growth has alerted many people to the virtual world phenomenon. It has been said that companies see SL as the latest fashionable web medium and are "hoping to show they're hip to the latest trends" and predicting that there will be some crossover into their RL business. The immersive environment of SL means users can "potentially become far more engaged with a brand than by simply browsing $a$ Web site with banner ads" which is echoed by Sibley Verbeck who says from "a good campaign, you can expect a lot of people to pick up and use your virtual product for hours".

The companies in SL are invariably using it in conjunction with actions in other market areas yet they "like to think of Second Life as ostensibly as real as a developing nation" and with it being so cheap to realise a SL presence it is worth the risk to gamble on success.SL has seen steady growth in users, design activity and companies realising a presence within it whereas most MMOGs see their users remain using the game for an average of a year, but as we have seen, SL is not really game".

Jerry Paffendorf, futurist in residence with the ESC believes SL has "the kind of growth curve that's characteristic of the way many important new technologies are adopted". So if SL stands the test of time like many predict it to, in what ilk will it be? Wladawsky-Berger is "convinced that such virtual world capabilities will profoundly transform business and related institutions in society" 


\section{Research Strategy}

Two questionnaires were used to be answered by a minimum of 20 subjects each. The first questionnaire focused on general SL users and concerned their experiences of SL and their exposure to design activity and companies. The second questionnaire focused on SL's use specifically as a design tool and concerned types of design, previous design experience and the advantages and disadvantages of SL as a design tool. The subjects have been identified from SL users found on internet forums specifically intended for SL discussion and interaction. This group of users were found to be the most experienced and knowledgeable about the SL platform and capabilities.

\subsection{Questionnaire design}

The questionnaires were designed to address the areas of the literature review which required additional research and clarification. The questionnaires identify statistical data regarding the use of SL as well as impartial user opinions and experiences. By using questionnaires with uniform question, presentation and style, large sample sizes and geographic areas can be covered in a way which is unbiased and fair. The subjects were required to answer a combination of open and closed questions which have been gathered and compiled into data tables and charts.

\section{SL Resident Questionnaires}

\subsection{Primary research limitations}

Feedback from questionnaire subjects has suggested the following limitations. Many subjects have different use sequences for SL so answering the questionnaire could only take into account certain scenarios. Their particular issue was tackled by making it clear to subjects that their answers should reflect their most common SL usage.

\subsection{Primary research conclusion}

Results from the questionnaires will inform the investigation into design activity within SL by supplementing and expanding upon the findings of the literature review. The findings from both sections will be cross referenced to find any areas that corroborate one another as well as areas of disagreement before conclusions are made.

\section{Analysis of Findings}

Findings from both primary and secondary research have been collected for analysis and discussion in the format of the research questions. As no primary research was carried out in to product design and the internet, this research question has been omitted from this section.

\subsection{SL and design SL use}

Questionnaire results indicate over 85\% of SL users are using SL on a daily basis which is supported by the statistics in the literature review which claim average users spend between 10 and 50 hours a week using SL with an average of 27.95 hours. The majority of subjects come from the UK and the USA however questionnaire subjects come from as far as Brazil, Canada, Italy, and Norway which is comparable to the areas where Internet usage peaks in general.

\subsubsection{Design tools}

Nearly all subjects have used SL's tools and features to produce or modify content with the majority having customised their avatars appearance and clothing. The SL toolset has its advantages as identified from the literature review however subjects feel that it is ultimately this that restricts them when creating in SL. The majority find the tools to be limited both in functionality and in the items they are able to produce.

The tools have been identified as any area of contention because of their lack of compatibility with external modelling software however findings from questionnaires have indicated that many subjects do not have the cad experience to justify this additional compatibility. The software most subjects have experience with is Adobe Photoshop or Illustrator though this is a 2D package which is very different to the modelling capabilities offered by SL. Very few subjects have experience of using more sophisticated' software such as Maya, AutoCad or Rhino.

\subsubsection{Design activity}

A high percentage of subjects have bought or sold content or land within SL which indicates these users have a premium account. Users with premium accounts are required to pay a $\$ 9$ a month fee so this indicates a commitment over time to SL. Approximately 1 in 3 people 
have had a SL job and are therefore gaining value from their time within SL along with those who have traded. The design jobs which subjects gave as occupations within SL included builder, clothing designer and scripter with less common jobs including architect, graphics and texture artist. Building is the primary area of design interest within SL however very few of these subjects have any experience of this trade in RL. This can be attributed to the fact the two jobs are very different with totally foreign skill sets required and also supports the notion that avatars can be very different from their RL user.

\subsection{Competition}

Although findings indicate a huge selection of virtual worlds for potential users to choose from the questionnaire results indicate a degree of loyalty towards SL, with over half of the subjects using only SL. This could be attributed to the level of positive press that SL has been exposed to as well as the differentiation between its platform and others. Increased pressure from competition can be expected in the future if SL continues to thrive and this could even come from the RL companies realising a presence within it.

\subsection{Design presence in SL}

\subsubsection{Companies in SL}

The company most people are aware of within SL is the Electric Sheep Company (ESC). The ESC was responsible for bringing AOL, Reuters and Major League Baseball to SL. Some of ESC's high quality work has undoubtedly been beneficial to the SL community; however, opinions regarding the company have been mixed. One subject attributes ESC as The leaders in the Walmartization of SL". Rivers Run Red is the company whose actions in SL mirror the ESC most closely however their presence is much less apparent to the subjects of the questionnaire.

Anshe Chung Studios perhaps the most notorious SL user thanks to her RL press coverage has worked with some of the questionnaire subjects. Experiences with Anshe Chung have been mixed with most work related to buying or selling her land often on Dreamland, the biggest real estate area after mainland on SL.
IBM is well known within SL as it controls several of its own islands. However, user experience suggests that IBM staff is isolated from the general population with little or no interaction. This lack of interaction has led to it being described as "a sterile environment" by one subject. Company interaction with Adidas and Toyota is also limited with its focus mainly associated with the use of their in world products and stores. There is no evidence of collaborative working on projects to date or use of SL users for concept feedback which were given as reason for their SL presence in RL press releases. Subjects report little or no experience of AbnAmro, Autodesk, Disney, Philips and Sun Microsystems.

The introduction of companies does have its advantages. The main benefit to date has been the investment into technology and infrastructure which these companies have made. Yet it is apparent that many companies are failing to deliver on all of their promises within $S L$, with their campaigns often more useful in getting RL press coverage than being worthwhile campaigns within SL. This coupled with the fact that users within SL do not appreciate being subjected to blatant product pitches means that large companies have been met with some derision. With many companies failing to use SL for creation, user interaction and collaboration there are fears that they could have ulterior motives for their presence, with some SL users fearing 'takeovers' and a 'big brother' environment which removes the freedoms afforded to average users.

\subsection{Future implications of SL on design}

With SL being such an open platform its potential for future developments remains open and undetermined. Despite being largely responsible for SL's future its current users are still undecided about the type of platform they see it becoming. The majority of subjects echo the sentiments of some leading figures in that they believe it will eventually become an interpretation of a 3D web environment or social network. Product design and creation is believed to be a viable avenue yet gaming is the platform which least subjects see SL becoming.

As was identified in the literature review many industry professionals see SL as a testing platform for designs and concepts. When asked to assume SL would be used as a design medium in the future; subjects identified 3D visualisation 
as the most viable design discipline, followed by user observation and physical product design. Subjects also believed that user feedback and research could be expanded upon current levels in the future.

Findings have shown that improvements to the software and its functionality will be required if SL is to maintain its impressive growth. With copyright issues being a point of contention for some time, subjects feel that the resolution of this problem would most improve the design capability of SL. An improved range of modelling tools is also desired, a view which is echoed by several experts in the literature review.

System performance has also been identified as an issue both from subjects and from SL developers themselves. Although SL's growing reputation has brought new residents and contributions to the virtual world, it has also brought a growing burden on the world's servers and software. This is compounded by the fact that all modelling needs to be carried out in the world with an apparent inability to use the native tools to edit offline. Therefore if SL is to continue its impressive growth, then measures need to be taken to ensure that it does not outgrow its capabilities.

\section{Results Analysis}

\subsection{Summary}

This research has examined the design activity found within SL from the perspective of users, companies and industry professionals with regard to the discipline of design, the Internet and alternative virtual worlds. This section gives conclusions about these areas in the format of the major research questions and gives recommendations for future studies.

\subsubsection{Product design and the Internet}

Over the past 15 years the World Wide Web has developed and evolved to a medium which people spend more time using than televisions. With many services such as Internet, TV, gaming and communication evolving towards a possible integration it may only be a matter of time until all aspects of our everyday lives revolve around it.

\subsubsection{SL and design}

SL has inevitably opened up many design opportunities which have not been capable in such a way before. Real time collaboration in a 3D environment has huge potential for designers to work on group projects without ever having to meet in real life. Not only does this offer a cost effective way of designing but also one that is environmentally and resource friendly. Companies are even being started specifically to prototype content which is produced within virtual environments.

If SL is to revolutionise design then it will not be the achievement of the world's developers but its users. SL has given people the tools and freedom to be "entrepreneurs dress in a way they could never feel comfortable doing in real life, build amazing works of art, and establish strong relationships among other similar residents". It is this revolution of user creativity which could have the greatest impact on the future of design.

\subsubsection{Design presence in SL}

The number of RL companies within SL is substantial with this amount expected to grow into the future. This can be attributed to the users, technology, money and most importantly the hype that it offers. Although their presence continues to grow; users can be forgiven for feeling apprehensive towards them as many of the companies activities seems to be geared towards gaining $\mathrm{RL}$ exposure rather than making a positive impact on SL.

By working with users or simply by observing their behaviours and in world actions, companies can expect to make connections with people which would otherwise be very difficult to replicate. "At the least, avatars offer a window into people's hidden preferences and $a$ means for achieving sustained consumer engagement with a brand". However, if companies are to make such connections with their users then their attitudes have to change. "To thrive in this environment, companies are going to have to learn how to yield power to users, and how to think in subtler, less money-hungry ways about the results of their efforts. "Companies undoubtedly have a future within SL but if this is to be truly beneficial to themselves and other SL users then a greater mutual understanding is paramount. If companies try to use the world as another advertising stream then their presence is liable to fail. 


\subsubsection{Future implications of SL on design}

The implications of SL on design could depend on how the internet and the platform of SL changes in the future. If the internet continues to develop towards a 3D platform then the implications that SL could have on design if IP rights are resolved, system performance is improved and user creativity continues to thrive could be huge. "By making the right intellectual property decisions, virtual worlds have the potential to be far more innovative than the real world".

User centred design takes into account the needs, wants, and limitations of the end user at each stage of the design process. SL allows designers to gain these insights from users first hand with the added capability of being able to see others designing for themselves. However, if the quality of content produced by these nondesigners is high, the future of design could be very different.

SL has given non-designers across the world the chance to design outfits, vehicles, games and the house of their dreams. However, by giving the user the power to create themselves, then it is feasible that SL could eventually remove the need for a conventional designer at all. Rapid prototyping advances mean that low quantities of products can be manufactured for a relatively low cost and in years to come this could become cost effective for single products, a revolution which would epitomise niche designing. So the future implication of SL on design could be that conventional designers are replaced with people designing products for themselves, first in a virtual environment and then in RL.

\section{Conclusion}

The aims of the research were to establish the extent of the design activity found within the virtual world of SL, the reasons users and companies are embracing virtual worlds and the future ramifications that this will have for design.

Despite having limited, published information and subjects to work from, the research establishes how SL was spawned from science fiction and internet evolution, how it has been embraced by normal people, designers and companies alike, and how it might shape the future of these people lives.
With technology developing and innovating so rapidly it is difficult to predict conclusively what the future ramifications that this will have on design will be. It could be that the Internet continues to develop towards a more integrated and interactive 3D system as trends suggest but is equally as likely that a totally new technology is developed which fundamentally changes our lives in the way that the internet did. The needs of the user however will remain the largest factor in the design of future products, and these will only be accessible through collaboration and interaction.

\subsection{Recommendations for future work}

With SL still in its infancy the findings of this research are based on only a few years of activity and statistics. This has meant that all results are constrained by a lack of data over a sustained period of time. Any future research would have the benefit of having a larger amount of information to investigate SL's performance over a number of years and in a number of areas. Monitoring companies, their activities and the relative success of different facets of design would give a greater indication of the future of SL than the short amount of data that has been accessible over the course of this study.

\section{REFERENCES}

1. HERMAN, A. (2010), Your Second Life. Cultural Studies, 20 (no. 2-3): 184-210.

2. HICKS, U. (2010), The Greening of SL. SL Business, 02 (no.1):12-15.

3. KOSTER, R. (2008), Game Developer's Conference

http://www.raphkoster.com/2002103/31lad c-round-up-31 (April2011)

4. NET $1 . \quad$ Second Life, http://en.wikipedia.orglwikilSecond Life (March 2011)

5. NET 2. (2010), The Power of Us, http:llwww.businessweek.comlmagazinelc ontent/05 25/b3938601.him (April 2011)

6. NET 3. (2009), Businessweek Online, http://images.businessweek.com (April 2011).

7. NET 4. Second Life, http:Ilwww.secondlife.com/ (February 2011). 
8. ONDREJKA, C. Escaping the gilded cage, http:Illindenlab.comlwhitepaperslEscapina Guilded Cage Ondrejka.pdf (April 2011)

9. PAGE, T., THORSTEINSSON, G., NICULESCU, A., Management of Knowledge in a Problem Based Learning Environment, Studies in Informatics and Control, 18(3), September 2009, ISSN 1220-1766, pp. 225-262.

10. PRATT, S. (2010). A Toy's Story. SL Business, 04 (no.1):8-15.

11. STEPHENSON, N. (2005). Snow Crash 1st ed. Penguin Books, London.
12. THORSTEINSSON, G., PAGE, T., LEHTONEN, M., NICULESCU, A., Innovative Technology Education in a Virtual Reality Learning Environment, Studies in Informatics and Control, 16(3), September 2007, ISSN 1220-1766, pp. 297-306.

13. UDEN, L., PAFFENDORF, J., VERBECK, S. WLADAWSKY-BERGER, T. (2011), Second Life, The Official Guide 1st ed. John Wiley \& Sons, New Jersey.

14. VEIGA, A. (2011), Virtual Design Wizards Keep Busy by 3-D Online Worlds, http:1/www.organic.comlabouilnewsdetail.i sp?815 (February 2011). 
